\title{
Study on Carbon Sequestration Benefit of Converting Farmland to Forest in Yan'an
}

\author{
Zhou M.C ${ }^{1}$, Han H.Z ${ }^{1 *}$, Yang X.J ${ }^{1}$, Chen $C^{1}$ \\ ${ }^{1}$ School of Tourism \& Research Institute of Human Geography, Xi'an International Studies University, Xi'an, China
}

\begin{abstract}
This paper takes Yan'anas the study area, analyses the current situation of the policy, calculates the carbon sequestration value by using the afforestation area and woodland area in Yanan in 2019, and explores its carbon emission trading potential. The conclusions are as follows: (1) the amount of carbon sequestration increased by $203575.5 \mathrm{t}$ due to the afforestation in 2019 in Yan'an. The green economy income of Yan'an can be increased by 5.8528 million RMB, because of it. The carbon sequestration value of total woodland is 120 million RMB, which can increase the forestry output value of Yan'an by $19.32 \%$. (2) The new carbon sequestration benefit of northern area is higher than that of southern area in Yan'an; the highest carbon sequestration benefit of returning farmland to forest isWuqi County's 35307.29t, and its value is 1.015 million RMB, it can be increased by $0.15 \%$ of the green economy income. (3) The industrial counties Huangling County and Huanglong County, the industrial counties Luochuan County and Yichuan County carry out carbon trading respectively, under the condition of ensuring the output value of the secondary industry in the industrial county, it can increase the green economy income of the total output value of Huanglong County and Yichuan County by $0.73 \%$ respectively.
\end{abstract}

\section{1 introduction}

The end of the 20th century, dust storms, severe environmental problems such as soil erosion and flood affected the ecological environment quality, hindered the development of society and economy, our country implemented based on ecological protection and economic sustainable development of returning farmland to forest policy. Returning farmland to forest ecological compensation measures stimulate farmers enthusiasm, prompted farmers to change land use way, then improve the ecological environment and adjust the income level and industrial structure of local farmers. At present, as an ecological protection policy involving the largest area and population, and with the largest amount of compensation, the conversion of farmland to forest has been implemented for more than 20 years. A number of studies show that the ecological environment in the area of the conversion of farmland to forest has been improved significantly. The conversion of farmland to forest has increased the vegetation coverage rate and reduced the ecological environment problems such as soil erosion and sand erosion. For example, during 2000-2015, the total area of farmland to forest was $127,500 \mathrm{~km}^{2}$, and that of farmland to grassland was $94,300 \mathrm{~km}^{2}$; the vegetation coverage of the project area, converting farmland to forest, increased by $0.17 \%$ annually; the average soil water erosion modulus and wind erosion modulus decreased by $0.13 \mathrm{t} / \mathrm{hm}^{2}$ and $0.68 \mathrm{t} / \mathrm{hm}^{2}$, respectively, which significantly increased the vegetation coverage and enhanced the soil erosion resistance in hilly and gully areas of the Loess Plateau, northeastern mountainous areas, sandy land, Yunnan-Guizhou Plateau and other regions ${ }^{[1]}$.

However, the ecological compensation policy for the conversion of farmland to forest has not achieved the goal of improving the income of farmers to achieve rural revitalization. It means the ecological compensation for the conversion of farmland to forest project can not fully compensate for the opportunity cost of reducing the area of cultivated land due to the implementation of the project. It is found that through the ecological compensation of money and grain, the transformation of land use mode, and the transfer of labor force to other industries, the income of farmers in the converted farmland areas has increased, but there are still some farmers who return to farmland and the participation of subsequent industries is not high; the reason is that the income of farmers in the converted farmland areas is lower than that in the non-converted farmland areas, and the income gap between urban and rural areas is larger ${ }^{[2]}$. And it is also proved that under the current compensation standard, the probability of damage of farmers who have returned farmland will increase with the increase of crop income from 2014 to 2030 [3]. comparing with non-farmers by propensity value matching method, farmers' income was reduced by $8.7 \%-10.9 \%$ by participating in the conversion of farmland to forest ${ }^{[4]}$.

After years of restoration, the vegetation of the converted farmland is a natural carbon sink in addition to 
meeting the needs of environmental management. Carbon sink refers to the process, activity or mechanism of absorbing carbon dioxide from the atmosphere through afforestation, vegetation restoration and other measures to reduce the concentration of greenhouse gases in the atmosphere. At present, the emission of greenhouse gases, mainly $\mathrm{CO}_{2}$, leads to global temperature rise and global climate change ${ }^{[5,6]}$, leading to frequent extreme climate events, which have varying degrees of impact on the economy, society and ecology of countries around the world. The world is committed to limiting the rise in global temperatures. The long-term goal of the Paris Agreement, signed in April 2016, is to limit the rise in global average temperatures to less than 2 degrees Celsius above pre-industrial times and to try to limit the rise in temperatures to 1.5 degrees Celsius. At the 75th session of the United Nations General Assembly on September 22, 2020, General Secretary Xi Jinping promised the international community that China would shoulder the responsibility of a major country and strive to achieve the low-carbon goal of "carbon neutrality" by 2060.The most effective way to achieve this goal is to focus on controlling and reducing $\mathrm{CO}_{2}$ emissions and increasing carbon sink. Therefore, as an important international action on climate change measures and the effective ways to realize China "carbon neutral" promised, "carbon emissions trading" (hereinafter referred to as "carbon trading") has been widely attention, it will be able to absorb $\mathrm{CO}_{2}$ in the atmosphere of the public goods "carbon sink" as a commodity in the market for carbon emissions rights trading ${ }^{[7]}$.Therefore, carbon trading has the ability to reduce global greenhouse gas emissions economically. It is an important way to realize the green development of national economy and a new driving force to promote the growth of rural economy. Exploring the carbon trading of returning farmland to forest areas not only plays a supplementary role in the realization of local rural revitalization, but also promotes the green development of rural economy and achieves the long-term goal of "carbon neutrality" in 2060.

Up to now, some scholars have started to study the carbon sink value of converting farmland to forest and the poverty alleviation effect of rural carbon trading. Studies have shown that the carbon sink function and economic value of conversion of farmland to forest are very significant. In Shaanxi Province, the annual amount of carbon sequestration and oxygen release of forest ecosystems according to different climate in the southern area and northern area, and found that the annual value of carbon sequestration and oxygen release were $328.27 \times 10^{8} \mathrm{RMB}$ and $732.35 \times 10^{8} \mathrm{RMB}$, with a total value of $1060.62 \times 10^{8} \mathrm{RMB}{ }^{[8]}$.It is contend that the conversion of farmland to forest has a significant function of carbon sink, after observing the different tree species in area of forestation in Sichuan Province and Chongqing City from 2003-2007 ${ }^{[9,10]}$.In recent years, scholars have paid attention to the role of carbon trading in promoting rural economy. Wang N.J. believes that carbon trading can obtain monetary benefits through low-carbon planting industry, clean production of breeding industry, integration of agriculture and other industries, combination of soil carbon sink and carbon trading, and making ecological livability through carbon sink, and the currency beneficiaries are "agriculture, farmers and farmers" [11]. Zeng W.Z. proposed the concept of "poverty alleviation by forest carbon sink" in combination with poverty alleviation in China's poverty-stricken areas ${ }^{[12]}$.However, few studies have focused on the potential of carbon sink and carbon trading from the perspective of promoting the greening of rural economy.

Therefore, this paper takes Yan 'an City of Shaanxi Province, the pilot of China's policy of returning farmland to forest, as the study area, and uses the data of forestation area of Yan 'an City from 1999 to 2019 and forest area of sub-county Yan 'an City in 2019. The carbon sink value of the converted farmland area is calculated to explore whether the economic income of local farmers can be increased with the help of carbon trading to realize the greening of economic income, and promote the development of rural green economy.It enriches the research cases on the carbon sink value of returning farmland to forest areas, provides support for the green development of converted farmland areas and rural revitalization, and seeks ways for the country to achieve the goal of "carbon neutrality".

\section{Overview of the study area}

\section{1 location of the study area}

Yan 'an City, located in the North of Shaanxi Province, belongs to the middle and lower reaches of the Yellow River, located in the middle and south of the Loess Plateau, $107^{\circ} 43^{\prime} \mathrm{E} \sim 110^{\circ} 46^{\prime} \mathrm{E}, 36^{\circ} 36^{\prime} \sim$ $37^{\circ} 35^{\prime} \mathrm{N}$, with a total area of $37037 \mathrm{~km}^{2}$, average altitude of $1200 \mathrm{~m}$ above sea level; The topography of the city is high in the northwest and low in the southeast. The landforms of the city are mainly typical loess tableland, ridge, hill and loess gully. Yan 'an City belongs to the semi-humid climate zone of warm temperate zone, with an average annual precipitation of $605.53 \mathrm{~mm}$. It is mainly concentrated in summer, with heavy rain and strong intensity. In winter, it is dry and windy from the northwest The territory is rich in natural resources, coal, oil, natural gas, iron ore and other natural resources, the southern forest coverage rate is higher, is the main ecological function area.

Yan' an City has jurisdiction over 2 districts, 1 city and 10 counties. In 2019, the regional GDP was 155.891 billion RMB; in terms of constant price, it increased by 9.1\% over the previous year, of which the added value of the primary industry was 13.807 billion RMB, an increase of $2.9 \%$; the added value of the secondary industry was 92.597 billion RMB, an increase of $9.8 \%$; the added value of the tertiary industry was 49.488 billion RMB, an increase of $9.8 \%$; the composition of the three industries is $8.9: 59.4: 31.7$.

\subsection{Policy implementation}

Deforestation and overgrazing by residents in the last 
century, as well as the landform features of loess gully, led to the shortage of local water resources, serious soil erosion, land desertification and other ecological crises, which not only reduced the quality of the local ecological environment, but also greatly hindered the development of economic society, and there are serious human and land environment problems. For this reason, Yan 'an took the lead in carrying out a large-scale project of returning farmland to forest nationwide in 1999. Since then, the total area of returning farmland to forest has been completed by $718,300 \mathrm{hm}^{2}$, and it is honored as the first city of returning farmland to forest (grass) in China. Figure 1 shows the change of afforestation area in Yan 'an City from 1999 to 2019. It can be seen from the figure that afforestation of Yan 'an City is more than 20 thousand hectares per year. According to Figure 1, the afforestation area of returning farmland to forest in Yan 'an City can be divided into five stages: 1999-2004 was the first stage, with the annual afforestation area exceeding 100 thousand hectares for six consecutive years. In 2003, the afforestation area exceeded 160 thousand hectares, which was the year with the largest afforestation area in history. From 2005 to 2008 was the second stage, and the afforestation area decreased by at least 60 thousand hectares compared with the first stage, which became the low point of afforestation area in the city in the past 20 years, maintaining at 20 to 40 thousand hectares. From 2009 to 2012 was the third stage, the afforestation area increased, but was still lower than that of the first stage, which was maintained at 40-60 thousand hectares. From 2013 to 2015 was the fourth stage, and the area was further increased and maintained at 60 to 90 thousand hectares. The period from 2016 to 2019 is the fifth stage, with the area decreasing and remaining at the same level as the third stage.

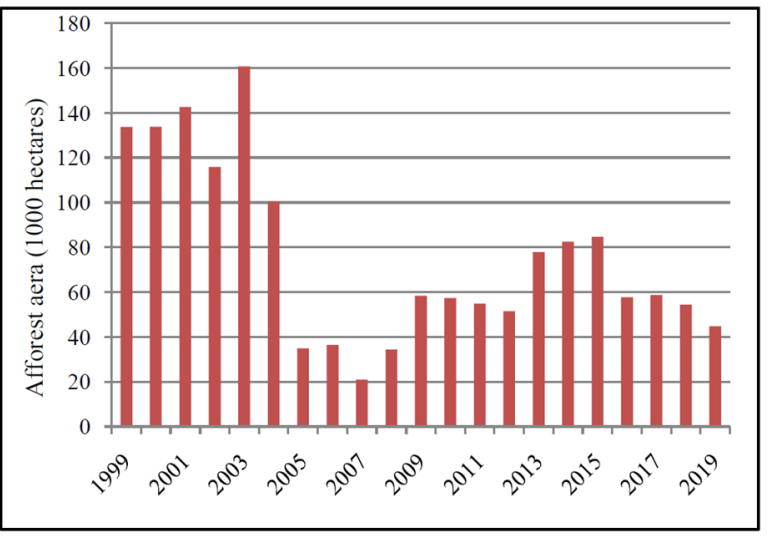

Fig.1 Reforestation area in Yan'an City, 1999-2019

\section{Materials and methods}

\subsection{Data sources}

The forestland area is derived from the cultivated land area data in the agricultural data ofYan 'an Statistical Yearbook in 2019.The data of barren hill afforestation area comes from the forestry production situation of sub-county in the agricultural data of Statistical Yearbook of Yan'an City in 2019. The data of the whole city includes the data of barren hill afforestation of four forest farms in Laoshan, Qiaoshan, Qiaobei and Huanglong of Yan 'an City, while the data of area of sub-county does not include the data of the four forest farms.The economic indicators are derived from the General and National Accounts section. Specific data are shown in Table 1:

Table1 Data on convert farmland to forest in Yan'an in 2019

\begin{tabular}{|c|c|c|c|}
\hline Counties & $\begin{array}{c}\text { Afforestation } \\
\text { area of barren } \\
\text { hills and } \\
\text { wasteland } \\
(10,000 \mathrm{mu})\end{array}$ & $\begin{array}{c}\text { Afforest area } \\
\text { (Thousand } \\
\text { hectares) }\end{array}$ & $\begin{array}{c}\text { Woodland } \\
\text { area (mu) }\end{array}$ \\
\hline $\begin{array}{c}\text { Baota } \\
\text { District }\end{array}$ & 11.83 & 7.89 & 321686 \\
\hline $\begin{array}{c}\text { Ansai } \\
\text { District }\end{array}$ & 11.28 & 7.52 & 2211365 \\
\hline $\begin{array}{c}\text { Zichang } \\
\text { City }\end{array}$ & 13.51 & 9.01 & 1286250 \\
\hline $\begin{array}{c}\text { Yanchang } \\
\text { County }\end{array}$ & 11.23 & 7.49 & 2909600 \\
\hline $\begin{array}{c}\text { Yanchuan } \\
\text { County }\end{array}$ & 2.52 & 1.68 & 691520 \\
\hline $\begin{array}{c}\text { Zhidan } \\
\text { County }\end{array}$ & 9.49 & 6.33 & 236700 \\
\hline $\begin{array}{c}\text { Wuqi } \\
\text { County }\end{array}$ & 26.39 & 17.59 & 2015242 \\
\hline $\begin{array}{c}\text { Ganquan } \\
\text { County }\end{array}$ & 8.00 & 5.33 & 2820671 \\
\hline $\begin{array}{c}\text { Fuxian } \\
\text { County }\end{array}$ & 4.65 & 3.10 & 5395825 \\
\hline $\begin{array}{c}\text { Luochuan } \\
\text { County }\end{array}$ & 6.01 & 4.01 & 1300238 \\
\hline $\begin{array}{c}\text { Yichuan } \\
\text { County }\end{array}$ & 9.25 & 6.17 & 2654589 \\
\hline $\begin{array}{c}\text { Huanglong } \\
\text { County }\end{array}$ & 4.05 & 2.70 & 3549931 \\
\hline $\begin{array}{c}\text { Huangling } \\
\text { County }\end{array}$ & 4.65 & 3.1 & 2822743 \\
\hline
\end{tabular}

\subsection{Research methods}

At the municipal level, this paper calculates the carbon sequestration amount and carbon sequestration value of the areas converted from farmland to forest in Yan'an in 2019 through the year-end forest area, barren hill afforestation area and net forest productivity, and makes a quantitative comparative analysis of the carbon sequestration value with the total GDP in 2019 and the output of various industries to explore the feasibility of carbon trading. At the county level, typical industrial counties and non-industrial counties were selected to calculate the amount and value of carbon sequestration and explore the feasibility of carbon trading between them.

In this paper, the calculation formula of carbon sequestration service function in the national standard 'Forest Ecosystem Service Evaluation Specification' (LY/ T1721-2008) was used to estimate the amount of carbon sequestration:

$$
\mathrm{G}_{\text {carbon fixation }}=1.63 \mathrm{R}_{\text {carbon }} \mathrm{AB}
$$

$G$ is the amount of carbon sequestration (unit: $t$ ), 1.63 
is the calculation constant, $\mathrm{R}_{\text {carbon }}=0.27$ is the proportion of carbon content in $\mathrm{CO}_{2}, \mathrm{~A}$ is the afforestation area (unit: $\mathrm{hm}^{2}$ ), and $\mathrm{B}$ is the productivity of tree species (unit: $\mathrm{t} / \mathrm{hm}^{2}$ ). Since the data of tree species planted in Yan 'an after returning farmland to forest can not be obtained from the statistical yearbook, some literature shows that the main tree species of plantation is Robinia pseudoacacia in Yan'an ${ }^{[13]}$.

Therefore, in this study, the productivity of tree species in Equation (1) B was substituted into the productivity of Robinia pseudoacacia. According to the research of $\mathrm{Ma}$ C.X., the productivity of Robinia pseudoacacia in northern Shaanxi was $4.56 \mathrm{t} / \mathrm{hm}^{2}$, so B was $4.56 \mathrm{t} / \mathrm{hm}^{2}$.

Carbon sequestration value is the amount of carbon sequestration multiplied by the unit price of carbon sequestration:

$$
\mathrm{U}_{\text {carbon fixation }}=\mathrm{G}_{\text {carbonfixation }} \mathrm{C}_{\text {carbon }}(2)
$$

Where: $\mathrm{U}$ is the value of carbon sequestration (unit: $\mathrm{RMB}$ ), $\mathrm{C}$ is the price of carbon sequestration (unit: RMB /t); In this paper, the average trading price of the carbon emission trading market in Shanghai, Guangdong, Shenzhen and other six pilot stable stages was taken as the unit carbon sequestration value, namely 28.75 RMB $/ t^{[14]}$.

\section{The influence of returning farmland to forest in Yan 'an}

Yan 'an as the first city of returning farmland to forest, and its economic benefit and ecological benefit of returning farmland to forest is very significant, and starting from the regional green economic growth and the perspective of sustainable development, to explore whether can through carbon emissions trading, to its ecological benefits further into farmland area economic growth momentum, boost rural revitalization. Forests, as the main body of terrestrial ecosystems, absorb and offset part of carbon dioxide produced by industrialization through photosynthesis of vegetation, making important contributions to the mitigation of greenhouse gas emissions and the response to climate change. However, carbon storage and carbon sink of forestation project of conversion of farmland to forest have maintained a steady growth trend and played a sustainable and stable function of carbon sink ${ }^{[15,16]}$.If the carbon sink function of returning farmland to forest can be utilized in carbon trading, the "green mountains and clear waters" of the converted farmland areas will be truly transformed into "golden hills and silver hills", and the green economic income of the converted farmland areas will be increased.

\subsection{Spatial distribution characteristics of the implementation of converting farmland to forest in Yan 'an}

As shown in Fig. 2, distribution map of afforestation area in each district and county of Yan 'an in 2019, from the spatial perspective of afforestation area, the afforestation area of Yan 'an in 2019 is generally higher in the north and lower in the south, which is consistent with the overall topography distribution of Yan 'an, and is generally opposite to the proportion of forest area and industrial output value at the end of 2018.In 2019, all districts and counties in Yan'an have afforested a total of 81.92 thousand hectares except the four forest farms, among which Wuqi County located in the northwest of Yan'an has the largest afforested area, with 17.59 thousand hectares, accounting for $21.47 \%$ of the total afforested area. The smallest afforestation area was 1.68 thousand hectares in northeast Yanchuan county, accounting for only $2.05 \%$. The areas with relatively high afforestation area in Yan'an are mainly distributed in Zichang County, Ansai County, Yan'an City and Yan Chang County in the north of the middle part of Yan'an City. The afforestation area of these four counties and cities is more than 6000 hectares.

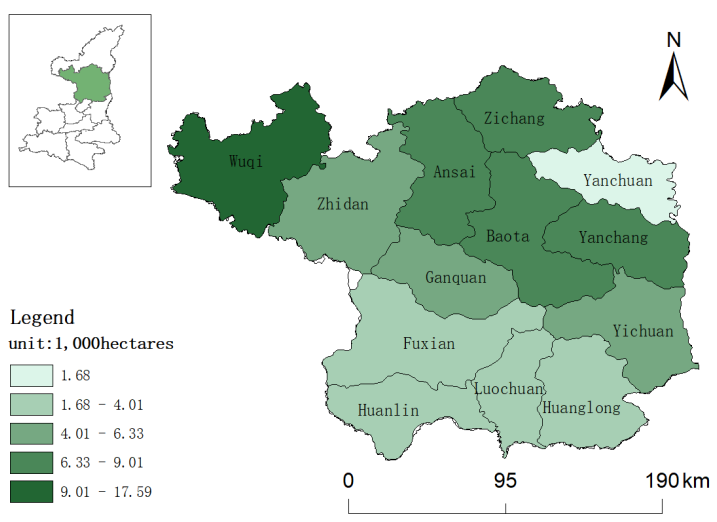

Fig.2 Distribution of reforestation area in Yan'an in 2019

\subsection{Analysis of carbon sink potential of each district and county in Yan 'an City}

In 2019, the afforestation area of barren hills and wastelands in Yan'an is 1,521,600 mu, namely 1,014,400 hectares. According to formula (1), the amount of carbon sequestration is about $20.36 \times 10^{4} \mathrm{t}$ of carbon sequestration, and according to formula (2), the value of carbon sequestration is 5,852,800 RMB, which reaches 0.36 of the total annual GDP of the city at the end of the year of 166.389 billion RMB. By the end of 2019, the forest land area of Yan'an was 2074,091 hectares. Since the area of various tree species in Yan 'an could not be obtained, assuming that the tree species was Robinia pseudoacacia, the carbon sequestration value obtained was calculated to be 120 million RMB, which accounted for $0.8 \%$ of the output value of the primary industry in Yan 'an in 2019 and $19.32 \%$ of the output value of forestry, which was 73 million RMB higher than the output value of fishery. As shown in Fig.3, the spatial distribution of newly added carbon sinks in Yan 'an districts and counties was also higher in the north and lower in the south, and the distribution pattern was consistent with that in Fig. 2. This was mainly because there was a multiple relationship between afforestation area and carbon sink benefits. 


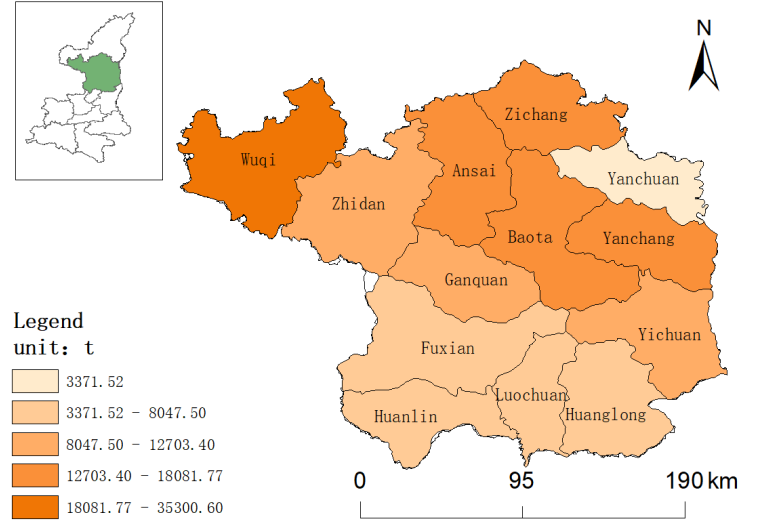

Fig.3. Distribution of new carbon sinks by districts and counties in Yan'an in 2019

As can be seen from Figure 3, the highest new carbon sequestration amount of all districts and counties in Yan 'an in 2019 is 35,307.29t in Wuqi County. According to Formula (2), if carbon sequestration amount is traded for carbon emission rights, the total output value of the county can be increased by 1.015 million RMB. For the economic development of the county, although it only accounts for 0.57 per 10,000 of the county's GDP at the end of 2019. However, the output value of its primary industry can be increased by $0.15 \%$, and the income belongs to pollution-free, low-carbon, environmental protection and sustainable green income. For farmers in the farmland returned areas, dividends can effectively supplement the subsidy of farmers in the farmland returned areas, increase their income, improve their enthusiasm for returning farmland to forests, forest cultivation and forest protection, and effectively curb the occurrence of multiple planting events.

As shown in Figure 4:Fuxian County has the largest forestland area, reaching 359.72 thousand hectares. Through the conversion of Formula (1) and (2), the amount of carbon sequestration is $721,900 \mathrm{t}$, and the value of carbon sequestration is 20,754,900 RMB, accounting for $0.37 \%$ of GDP and $1.5 \%$ of the primary industry. Although the proportion is relatively small, compared with the forestry output value of 13.83 million RMB in Fuxian County, Forestland carbon sequestration value is $6,924,900$ RMB.

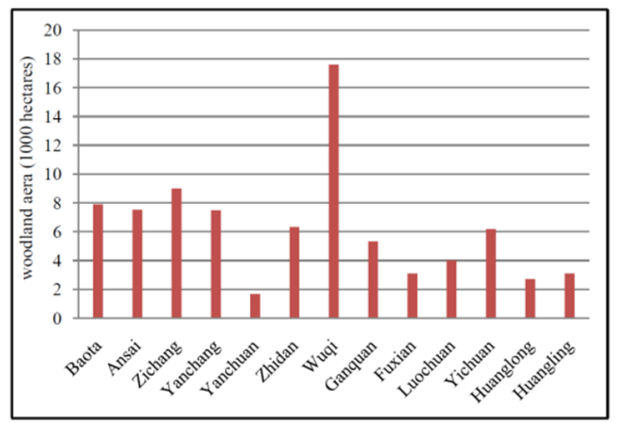

Fig. 4. Area of woodland in each district and county of Yan'an

According to the industrial proportion of each district and county in Yan 'an (Figure 5), Wuqi County with the highest proportion of secondary industry $(77.6 \%)$ and
Huangling County with the highest proportion of secondary industry $(77.4 \%)$ were selected as industrial counties, while Huanglong County and Yichuan County with a large proportion of primary industry and large woodland area were selected as non-industrial counties.In 2019, the afforestation area of barren mountains and wasteland in Huanglong County is 2700 hectares, and the increase of carbon sequestration amount is 5418.51t carbon compared with the previous year, and its value is 155,800 RMB.At the end of the year, the forest area was 236.67 thousand hectares, the carbon sequestration amount was 474,600 tons of carbon, and the carbon sequestration value was $13,654,700$ RMB.If carbon emission trading is conducted with Huangling County, an industrial county, the output value of the secondary industry in Huangling County can be increased by 13.6547 million RMB, $0.73 \%$ higher than the GDP at the end of 2019, while the output value of the secondary industry in Huangling County is guaranteed to be 14.382 billion RMB.If Yichuan County and Luochuan County carry out carbon emission right trading, the afforestation area of Yichuan County will be 6,166.67 hectares in 2019, with an additional 12,400 tons of carbon sequestration, worth $355,800 \mathrm{RMB}$. At the end of the year, the forest area was 17697 thousand hectares, the amount of carbon sequestration was 355,200 t, and the value of carbon sequestration was 10,210 thousand RMB.Yichuan County can increase 0.73 percent after the deal.

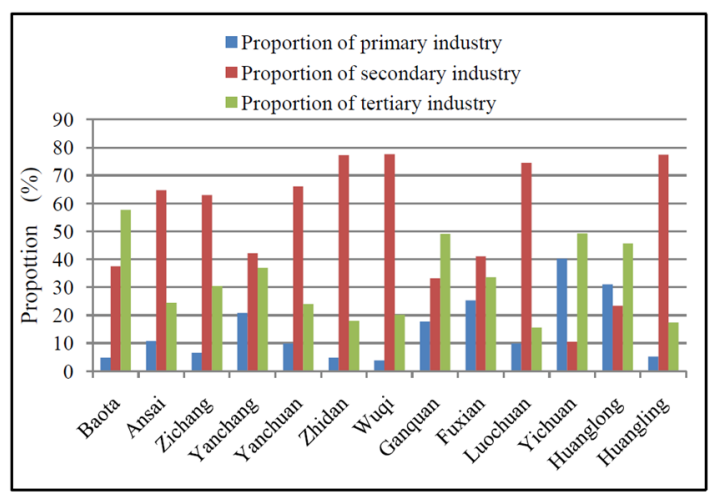

Fig.5. Industry share by district and county in Yan'an, 2019

\section{Discussion and conclusion}

After analyzing the impact of the project of converting farmland to forest at the present stage on Yan'an City, this paper calculates the additional carbon sequestration amount by using the afforestation area of wasteland and wasteland in 2019, calculates the carbon sequestration amount at the end of the year by using the forest area, and then selects the unit carbon sequestration price of China's carbon trading market which is more in line with the objective reality than the opportunity cost method. Calculate the potential of carbon emission trading in Yan 'an City in 2019 and analyze its impact. The conclusion is as follows:(1) The afforestation of wasteland and wasteland in Yan 'an in 2019 will increase the amount of carbon sequestration by 203,575.5 t. According to the trading price of the existing carbon trading market, its 
value will be 5,582,800 RMB, which is relatively small compared with the year-end GDP of the whole city. However, the value of forest land carbon sequestration will be 120 million RMB at the end of the year, and the post-transaction income will increase the forestry output value of Yan'an by $19.32 \%$. The income is 73 million RMB more than that of the fishery, which consumes more human resources.(2) In terms of the amount of new carbon sequestration, the benefit of new carbon sequestration was higher in the north and lower in the south. The maximum benefit of converting farmland to forest in Wuqi County was 35,307.29 t, and its value was 1.015 million RMB. If all transactions can be carried out, the output value of the county's primary industry can be increased by $0.15 \%$.(3) From the perspective of the woodland area at the end of the year, the amount of carbon sequestration was 721,900 tons, and its value was 20,754,900 RMB, which was 6.924,900 RMB larger than the forestry output value of 13.83 million RMB. According to the industrial structure of each district and county, carbon emission trading between Huangling County and Huanglong County can increase the total output value of Huanglong County by $0.73 \%$ while ensuring the output value of the secondary industry of the industrial county. After the trading between Luochuan County and Yichuan County, the same output value of Luochuan County can also increase the output value of Yichuan County by $0.73 \%$ if the output value of Luochuan County remains unchanged.

Assuming that yan 'an districts and counties to internal carbon trading, on economic development can not only guarantee the output value of the industry such as huangling, luochuan county, at the same time also can ensure YiChuan, huanglong, such as returning farmland area farmer's income, promote the development of returning farmland to forest the follow-up industry, thus a virtuous circle, prompting yan'an districts and counties have complementary advantages, coordinated development of green; In social aspect, because of carbon emissions rights trading returning farmland area increase farmers income, help for the farmers to protect existing trees, reduce the planting of the formation of the concept of environmental protection and enhancement, on the other hand, the farmers plant trees forest protection technology has also improved, so as to promote the development of forestry, to a certain extent, reduce the income gap between urban and rural areas; In terms of environmental protection, the development of clean energy in Yan'an has been innovated, the emission of $\mathrm{CO}_{2}$ has been effectively controlled, and the emission reduction task has been completed through internal trading.

Due to the lack of data such as tree species, stand age, ground grassland in the forest, grass debris, and tree cutting period in the analysis process, the calculated carbon sequestration amount and carbon sequestration value have some errors, so the carbon sequestration value of the project of converting farmland to forest in Yan 'an City needs to be further studied.

\section{Acknowledgments}

The authors would like to thank all the reviewers for their invaluable comments and suggestions on this manuscript. This research was funded by the Natural Science Basic Research Program of Shaanxi, grant number [2021JQ-770].

\section{References}

1. Huang L., Cao W., Zhu P.(2020) Regional differentiation characteristics of ecological effects of returning farmland to forest and grassland project. Acta. Ecol. Sin. , 40: 4041-4052.

2. Li G.P., Shi H.Y. (2017) Rural economic welfare effects of compensation for returning farmland to forests from a comparative perspective-- based on an empirical study of 79 counties in Shaanxi Province. Economic Geography, 37: 146-155.

3. Li G.P., Shi H.Y.(2015) The standard of ecological compensation for returning farmland to forest, farmers' behavior choice and profit and loss. Population Resources and Environment of China, 25: 152-161.

4. Zhang W., Xue J.H, Zhang X. (2019) The influence of the policy of returning farmland to forest on farmers' income and its mechanism. Rural Economic economy, 06: 130-136.

5. M. Tomas, A. Ernest (2021) The Evolution of Communicating the Uncertainty of Climate Change to Policymakers: A Study of IPCC Synthesis Reports. Sustainability, 13: 5 .

6. Sundquist E T.(1993) The global carbon dioxide budget. Science, (259): 934-939.

7. EHRENSTEIN V. (2018) Carbon sink geopolitics. Economy and society, 47: 1-25.

8. Ma C.X., Liu J.J, Kang B.W, Sun S.H, Ren J.H. (2010) Evaluation of carbon sequestration and oxygen release service function of forest ecosystem in Shaanxi Province in 1999. Acta. Ecol. Sin, 30: 1412-1422.

9. Chen X.G., Zhao X.H., Lu M., Tu Y., Yao P. (2009) Study on carbon sequestration potential of forest in the project of returning farmland to forest in Sichuan Province. Zhejiang Forestry Science and Technology, 29: 19-28.

10. Chen X.G., Zhang Y.P., Pan C.P., Chen W., CaiL.S.(2009) Estimation of carbon sequestration potential of forest in the project of returning farmland to forest in Chongqing. Journal of Central South University of Forestry Science and Technology, 29: 7-15.

11. Wang N.J., Tian Y., XuX. (2021) Carbon trading mechanism and path of rural revitalization of low-carbon development. Academic flow, 01: 109-119+192.

12. Zeng W.Z., Zhang J.Y., Yang F.(2016) Poverty alleviation by forest carbon sequestration: theoretical 
discussion and practical thinking. Rural economy, 05: $17-22$.

13. Li P.(2019) Study on photosynthetic physiological characteristics and ecological effects of Robinia pseudoacacia in Yan'an plantation, Yan'an University.

14. Zhang J., Sun L.H., Xing Z.C(2018) A study on the price volatility of China's carbon emissions trading market-- based on the data analysis of trading prices in six pilot carbon emission markets in Shenzhen,
Beijing, Shanghai and other cities. Price Theory and practice, 01: 57-60.

15. Jia S.W. (2013) Changes of forest carbon storage and estimation of economic value of carbon sequestration before and after returning farmland to forest-- A case study of Luoning County. Henan Agricultural Sciences,42: 68-71.

16. Jiao S.L., Ai Q.S.(2011) Economic benefit Analysis of carbon sequestration of the Project of returning cropland to Forest in Karst area of Central Guizhou. Ecological economy, 10: 69-72. 